\title{
O Artista Outsider no contexto Jaguarense: uma análise de perfis distintos
}

\author{
The Outsider Artist in the context Jaguarense: an analysis of different
} profiles

\author{
El artista forasteiro en el contexto Jaguarense: un análisis de diferentes \\ perfiles
}

\author{
Damaris de Lima Santos ${ }^{1}$ \\ Raicilane Barbosa de Jesus Santana ${ }^{2}$
}

\begin{abstract}
Resumo
O presente trabalho objetivou a elaboração de uma análise de dois perfis de artista outsider de Jaguarão-RS, tendo-os como objeto de estudo. A análise desenvolveu-se a princípio através de pesquisas bibliográficas sobre o tema, seguido de contato pessoal com os objetos de estudo em questão. Contou-se com a obtenção de dados através de entrevistas, observação participante, diário de campo, bem como registros fotográficos, a fim de entender minimamente a realidade e singularidade do artista outsider jaguarense. A metodologia aplicada possui natureza qualitativa. Dentro do contexto da análise, se pôde perceber que o artista desse segmento não possui um estilo que o defina, assim como não existe padrão a ser seguido, o que os une é apenas a não limitação a um cânone artístico, o não enquadramento nas instituições tradicionais das artes.
\end{abstract}

Palavras-Chave: Artista, Jaguarense, Outsider.

\section{Resumen}

Este estudio tuvo como objetivo la elaboración de un análisis de dos perfiles de artista forasteiro de Jaguarao-RS, que tiene como objeto de estudio. El análisis fue desarrollado inicialmente a través de la investigación bibliográfica sobre el tema, seguido por el contacto personal con los objetos de estudio en cuestión. Contó con la obtención de datos a través de entrevistas, observación participante, diario de campo y registros fotográficos con el fin de entender mínimamente la realidad y la singularidad del artista jaguarense forastero. La metodología aplicada es de naturaleza cualitativa. Dentro del análisis del contexto, podríamos ver que el artista de este segmento no tiene un estilo que se ajusta, así como estándar de lo que hay que seguir, lo que les une no se limita a un canon artístico, hay un marco de instituciones artes tradicionales.

Palabras claves: Artista, Jaguarense, Forastero.

\footnotetext{
1 Universidade Federal do Pampa - Unipampa; Campus Jaguarão, Rio Grande do Sul, Brasil. damaris.limas@gmail.com
}

2 Universidade Federal do Pampa - Unipampa; Campus Jaguarão, Rio Grande do Sul, Brasil. raici.miss@gmail.com 


\begin{abstract}
This study aimed to draw up an analysis of two artist profiles outsider Jaguarao-RS, having them as an object of study. The analysis was developed initially through bibliographic research on the topic, followed by personal contact with the objects of study in question. Counted on getting data through interviews, participant observation, field diary and photographic records in order to minimally understand the reality and uniqueness of the artist outsider jaguarense. The applied methodology has a qualitative nature. Within the analysis of the context, we could see that the artist of this segment does not have a style that set, as well as standard there is to be followed, what unites them is just not limited to an artistic canon, no framework in institutions traditional arts.
\end{abstract}

Keywords: Artist, Jaguarense, Outsider.

\title{
1. Introdução
}

O presente trabalho tem por intuito compreender minimamente o artista outsider, tomando por base dois artistas distintos presentes no contexto da cidade de Jaguarão ${ }^{3}$. Dentro da concepção de Becker (2008), outsider é aquele que está “fora de lugar”, o desviante. Sendo assim, os artistas acompanhados nesta pesquisa, de alguma forma, desobedecem a ordem posta. Um dos artistas é um estereótipo de motoqueiro e aparentemente insensível a um fazer artístico. O outro caso é uma dona de casa. O que os dois têm em comum é o não encaixe no modelo de "ser artista". Ambas as produções refletem o dia-a-dia dos seus autores, como aponta Oliveira (2012, p.37), "os trabalhos artísticos apresentam-se, cada vez mais, narrativos, autobiográficos e autorreferenciais".

Todos os grupos sociais fazem regras e tentam, em certos momentos e em algumas circunstâncias, impô-las. Regras sociais definem situações e tipos de comportamento a elas apropriados, especificando algumas ações como "certas" e proibindo outras como "erradas". Quando uma regra é imposta, a pessoa que presumivelmente a infringiu pode ser vista como um tipo especial, alguém de quem não se espera viver de acordo com as regras estipuladas pelo grupo. Essa pessoa é encarada como um outsider. (BECKER, 2008, p. 15).

Partindo desse princípio, pode-se afirmar que, os artistas independentes pesquisados fogem as regras de artistas consagrados, que em geral se dedicam unicamente ao fazer artístico. Muitas vezes a formação acadêmica na área das artes e a distribuição mercadológica de obras também podem ser consideradas regras para aqueles que se dedicam ao campo. Mas rompendo com esses costumes, os artistas outsiders encaram o fazer artístico como algo de simples espontaneidade do ato de criar. Nesse caso muitas obras são feitas sem a intenção de gerar lucros. As obras são feitas também fugindo de um contexto de técnicas e regras de acabamentos pré-estabelecidos.

\footnotetext{
${ }^{3}$ Jaguarão é um município do estado do Rio Grande do Sul situado no extremo sul do país na fronteira com o Uruguai. A cidade é reconhecida nacionalmente por seus sítios arquitetônicos, que constituem um acervo considerado sem similar em número e estado de conservação no estado. Segundo dados do IBGE (2015), Jaguarão possui uma população de 28.310 habitantes, distribuídos por uma área total de 2.054 km².
} 
Dentre os artistas observados para essa pesquisa, notou-se que uma em especial realiza pinturas em torno da religiosidade afro. Essa não possui características físicas de origem afro, porém possui estimulo pessoal para realização de tais obras. Nesse contexto, é relevante salientar que criações plásticas podem surgir no universo criativo "impregnadas de africanidade ou que valorizam uma poética afro-brasileira (pertencente a artistas negros e nãonegros) que se valendo dos signos, cores, materiais emotivos da tradição africana criam novos léxicos." (OLIVEIRA, 2012, p.37).

Quanto ao mercado de Arte é importante destacar que o mesmo conforme Moulin (2007), não detém de estilos prediletos, preocupando-se apenas com os que forem mais rentáveis e aos que aprovem a arte enquanto objeto de elevação de classe. O mercado atua sobre instituições como museus, espaços culturais, galerias de arte, universidades e é influenciador na produção de artista. Conforme Becker (1982), citado por Almeida (2009), os galeristas, marchand são comerciantes que precisam de espaço para apresentarem obras. Assim como precisam de compradores e artistas para tais produções. São os compradores que mantém as despesas das galerias. Para tanto, existem críticos que realizam discurso em torno das obras, despertando interesse nas mesmas. Em meio a esse meio artístico esses atores contribuem para construção e atribuição de valor as obras difundidas. O artista outsider nesse contexto sofre invisibilidade perante a sociedade. Havendo demandas quanto a políticas de incentivo a difusão e preservação das obras de tais artistas, principalmente em território fronteiriço onde existem diversas produções na área das artes visuais carentes de visibilidade.

Referente a subjetividade, pode-se afirmar que “(. . .) a subjetividade não é passível de totalização ou de centralização no indivíduo" (Guattari \& Rolnik, 1996, p. 31). O autor esclarece que a subjetividade implica em uma produção constante que ocorre a partir dos encontros e vivências com o outro. Para tanto, o outro pode ser compreendido como o outro social, mas também como a natureza, os acontecimentos, enfim, aquilo que gera efeitos nos corpos e nas formas de viver. Esses efeitos difundem-se através de múltiplos componentes de subjetividade que circulam no campo social. A arte outsider em vários momentos reflete o subjetivo, preza pelo diverso, expondo características peculiares do artista criador.

Tratando-se da estética da existência que se relaciona a um estilo próprio, Foucault (2004), considera que "artes da existência" devem ser entendidas como as práticas racionais e voluntárias pelas quais os homens não apenas determinam para si mesmos, regras de conduta, como também buscam transformar-se e modificar seu ser singular, e fazer de sua vida uma obra que seja portadora de certos valores estéticos e que corresponda a certos critérios de estilo. Assim, a estética da existência estabelece critérios estéticos do viver. 
A interação e pesquisa com dois perfis de artistas jaguarenses outsiders, permitiu conhecer suas criações, inspirações e estilos próprios que são negligenciados e pouco registrados. Sabe-se da importância em compreender os elementos presentes em suas invenções, as técnicas desenvolvidas pelos artistas e as características que compõem o ato criador dos dois perfis de artistas fronteiriços. Através de registros fotográficos e de diário de campo, prevê-se minimamente dar visibilidade aos artistas e reconhecimento de suas obras. Assim, pretende-se também discutir a importância da ação do produtor cultural ${ }^{4}$ no processo empoderador do artista outsider e da necessidade de políticas culturais voltadas a difusão da memória e reconhecimento de tais artistas.

\section{Objetivos}

Estabeleceu-se como objetivo central o desenvolvimento de uma análise de perfil de artista outsider jaguarense. Como objetivos secundários houve a promoção de diálogos com dois artistas, de modo a conhecer um pouco dessa produção, normalmente renegada e/ou negligenciada. Aspectos referentes as criações dos artistas, suas formas de pensar a arte e características representadas em suas obras são dados que se objetivou alcançar. Além disso, através dessa pesquisa se pôde ajudar a dar o mínimo de reconhecimento e visibilidade a esses artistas, ainda que só em âmbito acadêmico.

\section{Metodologia}

O processo de metodologia iniciou-se através de estudos bibliográficos sobre o tema central da pesquisa. Observou-se bases teóricas de autores influentes da área da produção outsider e do contexto das temáticas abordadas pelos artistas, objetos de estudo. Analises de vídeos também foram utilizadas como embasamento, proporcionando reflexões e aprofundamentos sobre o objeto (elemento) examinado. Optou-se por utilizar um método de pesquisa qualitativa, que se deu por meio da utilização de questionário, o qual se desenvolveu com um dos artistas.

O questionário foi composto de perguntas referentes as linguagens artísticas realizadas, aspectos sobre as primeiras criações, as inspirações do artista, as possíveis formações acadêmicas na área das artes, se já realizou oficinas culturais, questões quanto as comercializações de obras, as obras de mais apresso, as temáticas que mais apreciar para

\footnotetext{
${ }^{4} \mathrm{O}$ produtor cultural é o profissional que planeja, elabora e executa projetos e produtos culturais, seguindo critérios artísticos, sociais, políticos e econômicos. Ele também delineia políticas de investimentos no setor e analisa as propostas de patrocínio.
} 
retratar em pinturas e esculturas, a frequência do artista para realizar suas produções, as técnicas que desenvolve, os familiares que realizam criações artísticas, as motivações do artista, os locais que tem preferência para realizar criações, as dificuldades, as formas de pesquisas na área, as exposições realizadas pelo artista ou até mesmo o anseio em realizar. Além de documentação escrita via diário de campo, também foram feitos registros fotográficos das obras e de momentos de criação dos artistas.

\section{Resultados}

Através do estudo realizado com os dois perfis de artistas jaguarenses foi possível identificar várias linguagens artísticas realizadas, como pinturas, desenhos, entalhes em madeira, trabalhos com gesso, esculturas com sucatas e obras feitas com pirografia. Os artistas relataram que suas primeiras criações se deram desde a infância e as atuais inspirações se dão principalmente em ambientes solitários e de calmaria. Um dos artistas comentou que recentemente realizou oficinas culturais em escolas municipais da cidade, as quais não tiveram continuidade.

Os dois artistas apontaram não possuir conhecimento amplo em técnicas artísticas. Suas técnicas utilizadas partem de tentativas, as quais por vezes dão certo ou não. Eles abordaram que não costumam criar com intenções de comercializar suas obras, porém caso haja encomendas eles dedicam tempo para tais criações. Convém salientar que os dois artistas não são identificados e reconhecidos na cidade enquanto artistas. Ambos possuem interesse em expor suas obras, entretanto até o momento não tiveram patrocínio e devida atenção para tal ação.

Como dito anteriormente, foi entrevistado uma artista a qual realiza pinturas de religiosidade afro. Em suas obras, é notável a expressão de aspectos da tradição em que personagens específicos da religião são retratados de maneira detalhada. As cores, os traços e acabamentos utilizados exibem características importantes que apontam para a temática afro. Mesmo tendo iniciado seus processos de criação em torno dessa temática recentemente, a artista produz com facilidade e com características semelhantes a obras de muitos profissionais envolvidos no campo artístico.

$\mathrm{O}$ outro artista com perfil de motoqueiro comentou que iniciou suas criações com aproximadamente seis anos de idade. Contou que seu pai nessa época possuía uma borracharia e nela o artista passou a utilizar ferramentas e construir barcos, carros e aviões de madeira. Costumava passar várias tardes de sua infância em baixo de árvore desenhando. $\mathrm{Na}$ infância ele foi leitor de gibis com temas de faroestes, super heróis e ficção científica, de onde 
adquiriu suas primeiras inspirações para o desenho e a pintura. Suas atuais inspirações são seguem uma lógica pré-determinada, sendo que muitas vezes ele cria por espontânea vontade. Quando recebe encomendas procura criar aproximando-se ao máximo do que lhe é sugerido.

Esse artista, o qual se identificou como motoqueiro, expôs que não possui cursos na área das artes. Em 2012 atuou como professor voluntário de pinturas para alunos do ensino fundamental em escolas públicas do município. Em 2015 foi professor de grafite também para alunos de escolas municipais. Muitas das criações feitas por ele são doadas ou ficam espalhadas em locais que reside. Das produções que mais lhe chamam atenção para criar, o artista aponta a pintura, esculturas em madeira e realização de trabalhos com ferros. As temáticas predominantes em suas obras são em torno de lendas locais, natureza morta, máquinas, paisagens e caveiras. Quanto a frequência de suas criações varia conforme seu tempo disponível para tais. Ele destacou que exerce outras atividades, porém sempre que tem tempo livre aproveita para criar. Das técnicas que tem conhecimento, o artista aborda que foram totalmente adquiridas de maneira prática. Ele costuma mistura tintas, materiais diversos e conforme realiza suas obras, alcança conhecimento de produção.

$\mathrm{O}$ outsider motoqueiro relatou que seu pai quando ainda vivo, desenhava e pintava. Além disso citou um sobrinho artista, o qual o faz se recordar de sua própria infância. $\mathrm{O}$ sobrinho tem nove anos de idade e está sempre tranquilo e desenhando algo. $\mathrm{O}$ artista descreve que quando ele está em paz e de bem com o mundo, encontra motivação para criar algo. O fato de querer agradar e presentear alguém também o encoraja em suas produções. Sempre que sente vontade de criar, ele produz algo. Comentou que para tanto tem preferência para fazer suas obras em locais calmos e quietos. Porém caso necessário ele também desenvolve suas artes com pessoas em volta, estando elas o observando ou não.

As maiores dificuldades para o artista motoqueiro são em relação ao tempo. Ele salienta que desejaria ter maior tempo livre para o fazer criativo. Outras questões apontadas por ele foram referentes ao fato de que em sua adolescência ele não possuía acesso à internet. Entretanto, atualmente devido a facilidade de acesso aos meios tecnológicos, o artista busca sempre que pode referências no meio virtual. Destacou o apresso que possui para criar obras e pretende futuramente ter maior disponibilidade de tempo para se empenhar unicamente ao fazer artístico.

Foi possível identificar que as obras criadas pelos artistas surgem em sua maioria de forma espontânea. Um processo do fazer artístico em que prevalecem formas livres de expressão. Cada um dos artistas com suas peculiaridades demonstra ter domínio e autonomia do fazer criativo. Exploram o subjetivo de maneira a dar vazão a várias possibilidades de 
RELACult - Revista Latino-Americana de Estudos em Cultura e Sociedade

Revista Latinoamericana de Estudios en Cultura y Sociedad | Latin American Journal of Studies in Culture and Society V. 02, Ed. Especial, dezembro, 2016, p. 855-863 | periodicos.claec.org e-ISSN 2016/Atual: 2525-7870 | e-ISSN 2015/2016: 2447-018X

produções. Mesmo sem domínio aprofundado de técnicas de pinturas e do ato de esculpir, os artistas outsiders pesquisados demonstraram possuir diversidade de conhecimentos práticos e profundo envolvimento com o que realizam.

Sem dúvida são artistas com amplo apresso pelo ato da criação. Tanto o motoqueiro, quanto a dona de casa são artistas ainda desconhecidos por muitos. Para proporcionar difusão de suas obras é de fundamental importância a existência de políticas culturais e da ação de produtores culturais que atuem na mediação entre obras e públicos.

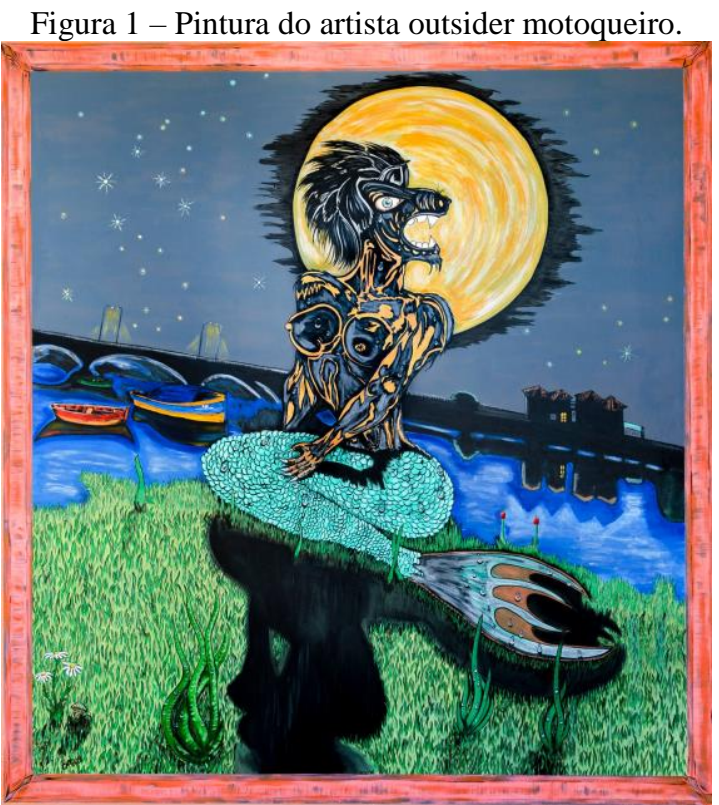

Fonte: Arquivo pessoal da pesquisa.

Figura 2 - Pinturas da artista outsider dona de casa.
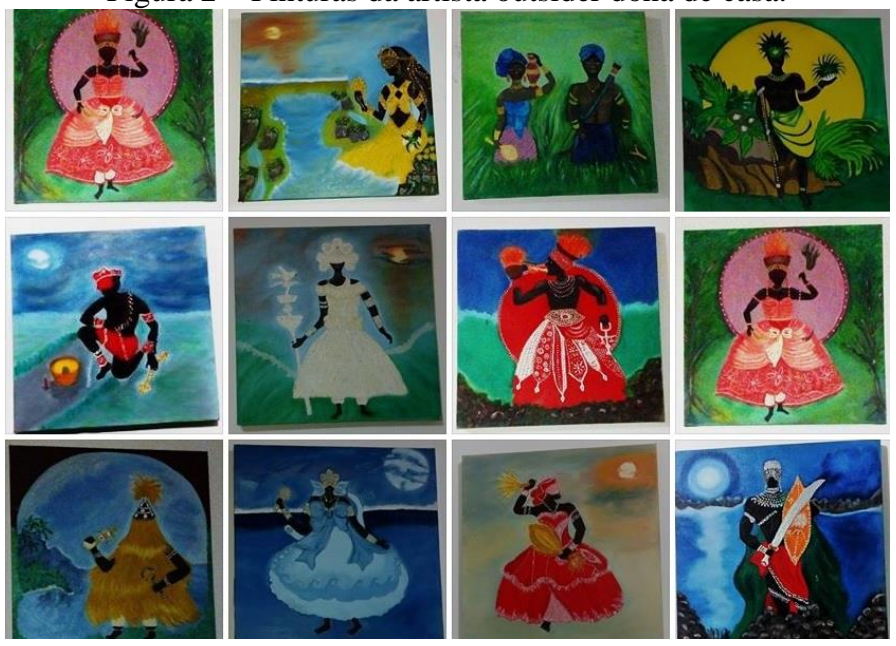

Fonte: Arquivo pessoal da pesquisa.

\section{Conclusões}


A partir da exposição feita acima, pode se compreender que o universo outsider não possui uma linha estética característica desses artistas, bem como o escoamento das suas produções não são uniformes e não passa normalmente pelos redutos tradicionais das artes, o artista desse segmento apresenta padrão em sua diferença, isto é, eles são um corpo estranho que se utilizam do que está disposto, mas não são entendidos pelos sistemas das artes enquanto artistas. E por isso, muitos dos outsiders têm dificuldade em perceber em si essa identidade artística, pois não veem em si a áurea de artista. Como se ser artista demandasse características ausentes neles.

A fim de atender as demandas de difusão de artistas outsiders, é imprescindível a criação de políticas públicas de cultura voltada a tais criadores. Convém presar pela memória e características identitárias de artistas fronteiriços, as quais são repletas de subjetividades. Para além disso, tem-se a figura do produtor cultural o qual tem função essencial no processo de empoderamento desses artistas, pois ele funciona enquanto elo do artista com os espaços sociais, isto é, o produtor tem consciência dos códigos e possui sensibilidade para lidar com o outsider e seu momento criador, sendo assim, o que o produtor faz é mediar, sem modificar o artista, sem adaptá-lo, mantendo-o dentro de sua singularidade sem necessariamente ser abarcado pelo sistema de artes convencional, mas ao mesmo tempo dando vazão a produção artística outsider.

\section{Referências}

ALMEIDA, Filipa. Mercado de arte contemporânea: construção do valor artístico e do estatuto de mercado do artista. Forum Sociológico Série II, 2009.

BECKER, Howard S. Outsiders: Estudos de Sociologia do Desvio. $1^{\text {a }}$ ed. - Rio de Janeiro: Jorge Zahar, 2008.

GUATTARI, F. \& ROLNIK, S. Micropolítica: cartografias do desejo. Petrópolis: Vozes, 1996.

FOUCAULT, M. A. Hermenêutica do Sujeito. 6.ed.São Paulo: Martins Fontes, 2004. MOULIN, Raymonde. $O$ mercado da arte: mundialização e novas tecnologias. Trad. Daniela Kern. Porto Alegre: Editora Zouk, 2007, 128p.

OLIVEIRA, Alecsandra. Memória da Pele - O Devir da Arte Contemporânea Afrobrasileira. Biblioteca Digital da Produção Intelectual - BDPI. Universidade de São Paulo, 2012.

Produção Cultural. Disponível em: $<$ http://guiadoestudante.abril.com.br/profissoes/comunicacao-informacao/producao-cultural688147.shtml>. Acesso em 03 agosto 2016. 
RELACult - Revista Latino-Americana de Estudos em Cultura e Sociedade

Revista Latinoamericana de Estudios en Cultura y Sociedad | Latin American Journal of Studies in Culture and Society V. 02, Ed. Especial, dezembro, 2016, p. 855-863 | periodicos.claec.org e-ISSN 2016/Atual: 2525-7870 | e-ISSN 2015/2016: 2447-018X

Rio Grande do Sul - Jaguarão. Disponível em: $<$ http://cidades.ibge.gov.br/xtras/perfil.php?lang=\&codmun=431100\&search=rio-grande-dosul|jaguarao >. Acesso em 17 agosto 2016.

Vídeo Diários de Campo por Silvio Coelho. Disponível em: $<$ https://www.youtube.com/watch?feature=player_embedded\&v=lozkrArK0LU Acesso em: 06 agosto 2016. 